\title{
Investigation of parallels between human basal metabolic features and local Earth magnetic field
}

\author{
Giedre Taletaviciene ${ }^{1}$, Rollin McCraty ${ }^{2}$, Vilius Pestininkas ${ }^{3}$, Alfonsas Vainoras ${ }^{4}$ \\ ${ }^{1}$ UPA Medical SPA, LT-66251 Druskininkai, Sveikatos 36, Lithuania \\ ${ }^{2}$ Department of Research HeartMath Institute, 14700 West Park, Ave. Boulder Creek, CA 95006, USA \\ ${ }^{3}$ Department of Mathematics University of Manchester, \\ Oxford Road, Manchester, Post code M13 9PY, United Kingdom \\ ${ }^{4}$ Institute of Cardiology, Lithuanian University of Health Sciences, \\ LT-50161, Kaunas, Sukilëlių 17, Lithuania \\ ${ }^{1}$ Corresponding author \\ E-mail: ${ }^{1}$ giedre.taletaviciene@upa.lt, ${ }^{2}$ rollin@heartmath.org, ${ }^{3}$ vilius.pestininkas@gmail.com, \\ ${ }^{4}$ alfonsas.vainoras@lsmuni.lt
}

Received 21 May 2021; received in revised form 17 June 2021; accepted 27 June 2021 DOI https://doi.org/10.21595/chs.2021.22123

Check for updates

Copyright $(2021$ Giedre Taletaviciene, et al. This is an open access article distributed under the Creative Commons Attribution License, which permits unrestricted use, distribution, and reproduction in any medium, provided the original work is properly cited.

\begin{abstract}
The human body, even at rest, needs energy to perform necessary physiological functions. Strict conditions are required for measuring basal metabolic rate (BMR). Many factors that have a direct impact on BMR including the condition of autonomic nervous. All living systems are affected by external and internal environments. One factor in the external environment is the Earth's magnetic field, which fluctuates over a wide frequency range. A series of studies indicate that low frequency magnetic fields can affect cellular mitochondrial activity and impacts every cell's metabolism. Information on gas metabolism during respiration was obtained by indirect calorimetry using a system where the gas flow was continuously analyzed. Time varying local Earth magnetic field data were recorded at a magnetometer site located in Lithuania using 2 induction coil magnetometers. For all magnetic field data, power spectral density PSD was calculated for every hour (fast Fourier transformation) in the band between 0.32 to $36 \mathrm{~Hz}$. Investigations of metabolic rate were performed in Lithuanian during 2016-2020 years. We assessed 395 persons: 116 men and 279 women. Conclusions: 1) Oxygen consumption has significant negative correlation with local geomagnetic field activity; 2) Metabolic rate decreases with increases in local geomagnetic time varying field power; 3) Measured metabolic rate decreases with increase of local geomagnetic field power.
\end{abstract}

Keywords: basal metabolic rate, local Earth magnetic field, spyroergometry.

\section{Introduction}

The human body, even at rest, requires energy to perform necessary physiological functions, such as the contraction of the muscles of the heart and respiratory system, the maintenance of potential gradients across cell membranes, and the regeneration and recovery of cells. The body's energy needs are met either through food intake or through the use of accumulated reserves [1]. The energy released by the cells is mainly used to synthesize adenosine triphosphate (ATP) from adenosine diphosphate (ADP) and inorganic phosphates. Fasting energy stores are mobilized by hormones (including glucagon, growth hormone, and cortisol) and oxidized to maintain an adequate energy supply [1]. The basal metabolic rate (BMR) is a measurement of the number of calories needed to perform your body's most basic (basal) functions, like breathing, circulation and cell production. BMR is most accurately measured in a lab setting under very restrictive conditions.

The subject should have fasted, be physically and psychologically relaxed, and at an appropriate ambient temperature [2]. These conditions can be difficult to establish in practice, so a resting metabolic rate (RMR) study is often chosen to obtain more realistic study data. The RMR is estimated to be about $10 \%$ higher during a 24-hour period than the BMR [1]. 
The main, and most important determinants of BMR are: 1) weight as energy consumption is determined by cellular mass, therefore body weight is the most important factor in determining BMR; 2) gender, BMR is related to muscle mass, which is higher in men than in women, and the metabolic rate in women is $5-10 \%$ lower than in men; 3) age, BMR, expressed in $\mathrm{kg}$ of body weight, and the active cell mass varies from infancy to old age; 4) genetic factors, there are genetic differences in human metabolic rate, although they are still poorly studied [1].

The values and coefficients (sex) of these factors (height, weight, and age) are used in various formulas of theoretical BMR calculation (Harris - Benedict, Scofild et al.) [1].

Of course, there are many other factors that have a direct impact on BMR such as certain drugs and foods (e.g., nicotine, caffeine, amphetamine, capsaicin in hot pepper, appetite suppressants), diseases and related factors (e.g., fever, thyroid disease, cancer) and environmental conditions (e.g., severe heat or cold) [1], [2]. Starvation can reduce BMR as the body tries to adapt to a life-threatening situation, as can dieting because they are trying to lose weight [1], [3]. If the lifestyle is sedentary, BMR usually accounts for about $60-70 \%$ of daily energy expenditure [1]. The activity levels of autonomic nervous system has a significant effect on BMR too [3].

All biological systems are affected by both the external and internal environments. One factor in the external environment is the Earth's time varying magnetic field, which fluctuates over a wide frequency range. One aspect of $f$ these oscillations are called Schuman resonances [4]. These fields can affect almost every cell in living systems [5]. A series of research studies indicates that low-frequency magnetic fields can affect cellular mitochondrial activity and have impact into every cell metabolism [6], [7].

It is well known that geomagnetic field line resonances and the Schuman resonances occurring in the cavity between the Earth and the ionosphere produce resonant frequencies that coincide directly with the frequencies of the human brain, autonomic nervous system, and cardiovascular system [4], [8].

Research shows that daily activity of the autonomic nervous system not only responds to changes in solar and geomagnetic activity, but is also synchronized with time-varying magnetic fields associated with geomagnetic field line resonances and Schumann resonances that coincide with physiological rhythms [9], [10], [11] and may affect human health [12], [13], [14].

An important aspect in this area of research is to understand the differences between global and local GMFs. There is a lot of research on global GMA and health outcomes, but it was not possible to measure our local GMA in Lithuania due to the lack of a local magnetometer. Since the GMA detection facility was installed in Lithuania in 2014 by HeartMath Institute (California, USA), we now have the opportunity to obtain accurate local data and conduct studies examining the potential links between GMA and human health in Lithuania [9], [15].

The aim of this study: to investigate the potential relationships between the basal (resting) metabolism of the human body and the local Earth time varying magnetic field activity.

\section{Methods}

\subsection{Research methodology}

Medical device used for the research: spyroergometry system Metacontrol 3000, (Cortex Biophysik GmbH, Germany). Information on gas metabolism during respiration was obtained by indirect calorimetry where the gas flow was continuously analyzed. The study was conducted in the morning before the subject had eaten. The subject laid on the couch for 15 minutes psychologically and physically relaxed. Breathing was performed through a special gas flow recorder. $\mathrm{O}_{2}$ consumption and $\mathrm{CO}_{2}$ emissions were continuously analyzed and their ratio (RQ) was calculated. The best quality $5 \mathrm{~min}$ section was selected from the $15 \mathrm{~min}$ recording (automatically selected by the computer). The results were analyzed and mean resting metabolic rate (M_RMR) was calculated and compared with the norm resting metabolic rate (N_RMR), where $\mathrm{RMR}=\mathrm{BMR}+10$ percent. 


\subsection{Measure of local earth magnetic field}

Time varying local Earth magnetic field data were recorded at the GCI magnetometer site located in Lithuania using 2 Zonge Engineering Inc. (Tucson Arizona) ANT4 induction coil magnetometers. Magnetometer records data in two directions - north/south and east/west. Signals from the magnetometer were collected with a 24 bit ADC (Symmetric Research, Las Vegas NV) at $130 \mathrm{~Hz}$ frequency. For all data the power spectral density (PSD) was calculated using a FFT (fast Fourier transformation) for every hour [16]. Power of spectral density was calculated in 0.32 to $36 \mathrm{~Hz}$ frequency range from the Lithuanian (GCI003) magnetometer for East - West direction (E-W). This frequency band embraces the same frequency bands that are typically used for human brain waves [17]. Asses to magnetometric data (for GCI003) are in web page https://www.heartmath.org/research/global-coherence/gcms-live-data/.

\subsection{Participants}

During 2016 - 2020 years, 395 persons were investigated: 116 men and 279 women. Mean age for men (M+/-SD) was 50.05+/- 13.12 years, for women $-44.52+/-12.67$ years. Body mass index (BMI) for men was $28.95+/-6.87\left[\mathrm{~kg} / \mathrm{cm}^{2}\right]$ and for women $27.05+/-5.97\left[\mathrm{~kg} / \mathrm{cm}^{2}\right]$. Investigations of metabolic rate were performed in Lithuanian, Druskininkai, Medical SPA Center „UPA".

The study was carried out with Kaunas Regional Biomedical Research Ethics Committee Permision No. BE-50.

\section{Results}

The changes in local Earth time varying magnetic field (LEMF) mean monthly power is presented in Fig. 1. It was lowest in year 2016, then increase till 2018.

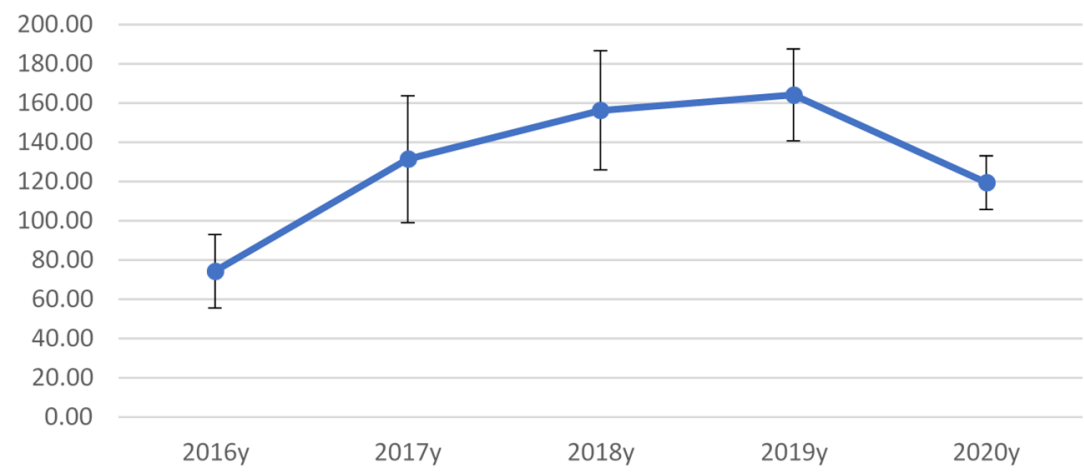

Fig. 1. Mean monthly of local magnetic field during 2016-2020 years

The number of men and women, for whom the RMR was measured is shown in Fig. 2. The number of women is about twice than men. During the year 2020, only a small number of participants were assessed due to the Covid-19 pandemic.

The ratio between the number of men and women shown in Fig. 3. It is interesting to see that curve has a strong negative correlation with the changes in LGMF in Fig. 1.

For individuals who were assessed during the study period, we observed a positive correlation between their age and local GMF $(\operatorname{corr}(\mathrm{r})=0.2822, p<0.05)$. Although this is a weak positive correlation, it potentially indicates the need for older people to use spa services to achieve bodystrengthening effects under the most favorable LGMF conditions, although apparently this was done on an intuitive level without sufficient information.

The values of RMR for women and men are shown in Table 1. Measured M_RMR for women 
was less than for men. Correlations between M_RMR and LGMF were significantly negative (Table 1).

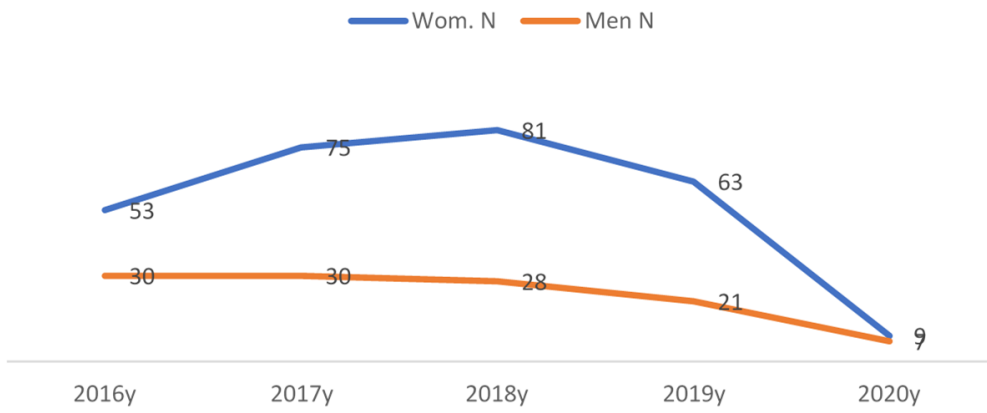

Fig. 2. Number of studied men and women in $2016-2020$ years

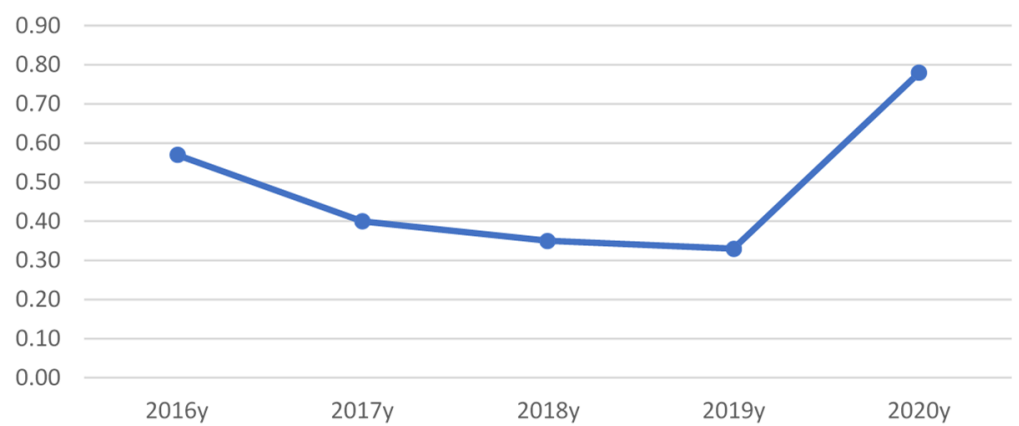

Fig. 3. Ratio between investigated number of men and women

Table 1. Values of RMR for women and men and their correlations with LGMF activity during the years between 2016-2020

\begin{tabular}{|c|c|c|c|}
\hline RMR & N_RMR & M RMR & $\triangle$ RMR $\%$ \\
\hline Women & 1743.04 & 1775.2 & 2.21 \\
\hline Men & 1757.2 & 1790.82 & 2.21 \\
\hline Corr (LGMF/RMR), Wom. & -0.0608 & $\mathbf{- 0 . 1 9 5 6}$ & $\mathbf{- 0 . 2 2 9 1}$ \\
\hline Corr (LGMF/RMR), Men. & $\mathbf{- 0 . 2 0 0 6}$ & $\mathbf{- 0 . 2 5 9 1}$ & -0.1487 \\
\hline Bold numbers shows that the result was significant at the $p<0.05$ level \\
\hline
\end{tabular}

Annual changes of M_RMR are shown in Fig. 4. The correlations with M_RMR has tendency to be negatively correlated. It means, that in constant energy consumption in human organism, measured RMR is less, when power of LGMF fluctuations in low frequencies increase. What can show, that LGMF itself, support basal metabolic rate.

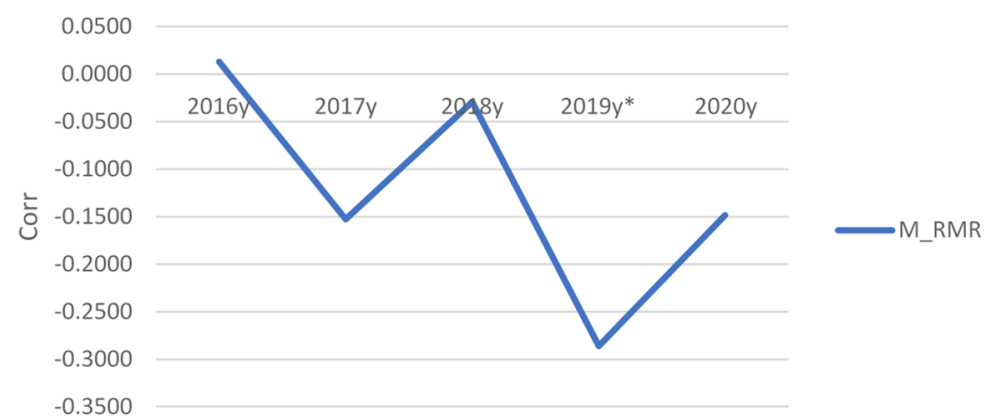

Fig. 4. M_RMR annual changes during 2016-2020 years 
Oxygen $\left(\mathrm{VO}_{2}\right)$ consumption, as well as carbon dioxide $\left(\mathrm{VCO}_{2}\right)$ emissions, was negatively correlated with LGMF intensity and, these rates were slightly lower for women than for men (Table 2).

Table 2. Values of consumed $\mathrm{O}_{2}$ and produced $\mathrm{CO}_{2}$ for investigated women and men and their correlations with LGMF during 2016-2020 years

\begin{tabular}{|c|c|c|c|}
\hline Gas exchange (X) & $\mathrm{VO}_{2}$ & $\mathrm{VCO}_{2}$ & $\mathrm{RQ}$ \\
\hline Women & 0.25 & 0.22 & 0.9 \\
\hline Men & 0.26 & 0.23 & 0.9 \\
\hline Corr (LGMF/X), Wom. & $\mathbf{- 0 . 2 2 6 7}$ & $\mathbf{- 0 . 2 0 9 7}$ & 0.0167 \\
\hline Corr (LGMF/X), Men. & $\mathbf{- 0 . 2 9 0 9}$ & $\mathbf{- 0 . 2 2 6 2}$ & $\mathbf{0 . 1 7 4 2}$ \\
\hline Bold numbers shows that result was significant at the $p<0.05$ level \\
\hline
\end{tabular}

\section{Discussion}

The human metabolic parameters studied over a five-year period undoubtedly had many influences modulating their changes, such as meteorological factors, and different seasons. However, some, albeit weak, links with the LGMF have emerged. We find it interesting and potentially important that the correlations of these relationships are negative. The BMI of the subjects did not differ significantly from year to year. However, the data show that a stronger power in the resonant frequencies in LGMF requires less energy resources (Table 2) in order to maintain the same body functionality at rest. Given the information [6], [7] that the low-frequency magnetic field stimulates cellular mitochondrial activity, it can be suspected that, in fact, the efficiency of $\mathrm{O}_{2}$ utilization increases with stronger LGMF activity (resonant frequencies), resulting in the cells have less need for oxygen to the cellular efficiency. We believe that this is supported by the data from this study.

A number of studies have shown that reliable correlations between both LGMF [17] and GMF activity [18] and human organism functionalities are observed. While studies examining magnetic field disturbance show negative effects on health outcomes, a growing body of research is indicating that increases in the resonant frequencies in the Earth's magnetic fields is positively associated with the decrease of pathological processes. This link is successfully used in the course of spa treatment, the success of which is partly due to increased activity of LGMF. Indirectly, these factors apparently also modulate the arrival of women and men in spa and change the relationship between men and women in them.

\section{Conclusions}

This study examined the relationships between the basal metabolic rate and the spectral power in Earth's local magnetic field in the frequency range between 0.32 to $36 \mathrm{~Hz}$ in 395 participants over a 5-year period. Several surprising and important correlations were found. It was shown that the increased Local Earth magnetic field activity (resonant frequencies) appear to have significant positive impact on human metabolic features and show an increase the efficiency of organism functionality. Oxygen consumption had a significant negative correlation with local geomagnetic field activity and the resting metabolic rate decreased with increase of local geomagnetic field power. Therefore, this study adds to the growing body of research suggesting that increases in the resonant frequencies in the Earth's magnetic fields is positively associated with the decrease of pathological processes.

\section{References}

[1] S. Sharma, T. Sheehy, F. Kolahdooz, M. Barasi, Mityba, Vilnius: Vaistu žinios, 2017.

[2] C. Compher, D. Frankenfield, N. Keim, and L. Roth-Yousey, "Best practice methods to apply to measurement of resting metabolic rate in adults: a systematic review," Journal of the American 
INVESTIGATION OF PARALLELS BETWEEN HUMAN BASAL METABOLIC FEATURES AND LOCAL EARTH MAGNETIC FIELD. Giedre TaletaViciene, Rollin McCraty, Vilius PestininKas, Alfonsas Vainoras

Dietetic Association, Vol. 106, No. 6, pp. 881-903, Jun. 2006, https://doi.org/10.1016/j.jada.2006.02.009

[3] C. Shibao, M. S. Buchowski, K. Y. Chen, C. Yu, and I. Biaggioni, "Chronic sympathetic attenuation and energy metabolism in autonomic failure," Hypertension, Vol. 59, No. 5, pp. 985-990, May 2012, https://doi.org/10.1161/hypertensionaha.111.190157

[4] W. O. Schumann, "Über die dämpfung der elektromagnetischen eigenschwingungen des systems erde - luft - ionosphäre," Zeitschrift für Naturforschung A, Vol. 7, No. 3-4, pp. 250-252, Mar. 1952, https://doi.org/10.1515/zna-1952-3-404

[5] A. A. Al Abdulgader, "Quantum consciousness and the heart based resonant frequencies theory," Archives in Neurology and Neuroscience, Vol. 9, No. 4, pp. 1-10, Jan. 2021, https://doi.org/10.33552/ann.2021.09.000719

[6] A. L. Buchachenko and D. A. Kuznetsov, "Magnetic field affects enzymatic ATP synthesis," Journal of the American Chemical Society, Vol. 130, No. 39, pp. 12868-12869, Oct. 2008, https://doi.org/10.1021/ja804819k

[7] D. Wang et al., "Cellular ATP levels are affected by moderate and strong static magnetic fields," Bioelectromagnetics, Vol. 39, No. 5, pp. 352-360, Jul. 2018, https://doi.org/10.1002/bem.22122

[8] I. Timofejeva et al., "Identification of a group's physiological synchronization with earth's magnetic field," International Journal of Environmental Research and Public Health, Vol. 14, No. 9, p. 998, Sep. 2017, https://doi.org/10.3390/ijerph14090998

[9] R. Mccraty, M. Atkinson, V. Stolc, A. Alabdulgader, A. Vainoras, and M. Ragulskis, "Synchronization of human autonomic nervous system rhythms with geomagnetic activity in human subjects," International Journal of Environmental Research and Public Health, Vol. 14, No. 7, p. 770, Jul. 2017, https://doi.org/10.3390/ijerph14070770

[10] K. Janashia, L. Tvildiani, T. Tsibadze, N. Invia, V. Kukhianidze, and G. Ramishvili, "Reactions of the autonomic nervous system of healthy male humans on the natural and simulated conditions of the geomagnetic field," American Journal of Clinical and Experimental Medicine, Vol. 8, No. 4, p. 69, 2020, https://doi.org/10.11648/j.ajcem.20200804.12

[11] S. Chernouss, A. Vinogradov, E. Vlassova, Geophysical hazard for human health in the circumpolar auroral belt: evidence of a relationship between heart rate variation and electromagnetic disturbances," Natural Hazards, Vol. 23, pp. 121-135, 2001, https://doi.org/10.1023/A:1011108723374

[12] T. A. Zenchenko and T. K. Breus, "The possible effect of space weather factors on various physiological systems of the human organism," Atmosphere, Vol. 12, No. 3, p. 346, Mar. 2021, https://doi.org/10.3390/atmos12030346

[13] H. Morimoto, "Human health response to geomagnetic disturbances," International Journal of Engineering and Applied Sciences (IJEAS), Vol. 7, No. 9, Sep. 2020, https://doi.org/10.31873/ijeas.7.09.13

[14] I. V. Sterlikova, "On human body reaction to a changed geomagnetic background," Aerospace and environmental medicine, Vol. 49, No. 4, pp. 47-53, 2015.

[15] R. Joffë-Luinienè, Biopsychosocial Wellbeing and Its Relationship with Geomagnetic Field Fluctuations in Lithuania, Doctoral Dissertation, Medical and Health Sciences, Lithuanian University of Health Sciences, 2020.

[16] M. Landauskas, A. Vainoras, and M. Ragulskis, "Algebraic and spectral analysis of local magnetic field intensity," Lietuvos Matematikos Rinkinys, Vol. 56, pp. 54-59, Dec. 2015, https://doi.org/10.15388/lmr.a.2015.10

[17] G. Jaruševičius, T. Rugelis, R. Mccraty, M. Landauskas, K. Berškienè, and A. Vainoras, "Correlation between changes in local earth's magnetic field and cases of acute myocardial infarction," International Journal of Environmental Research and Public Health, Vol. 15, No. 3, p. 399, Feb. 2018, https://doi.org/10.3390/ijerph15030399

[18] V. Vaičiulis et al., "Associations between space weather events and the incidence of acute myocardial infarction and deaths from ischemic heart disease," Atmosphere, Vol. 12, No. 3, p. 306, Feb. 2021, https://doi.org/10.3390/atmos12030306 


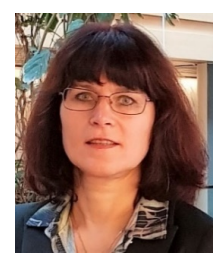

Giedrė Taletavičienė, Ph.D., doctor, Upa Medical SPA, Druskininkai. Doctoral Dissertation "Changes of electrocardiographic parameters and their concatenations during whole-body cryotherapy and peloidotherapy procedures" 2014 in Lithuanian University of Health Sciences. Is working on curortology and recreation medicine, on ECG nonlinear analysis and is studying local magnetic field and human health interactions.

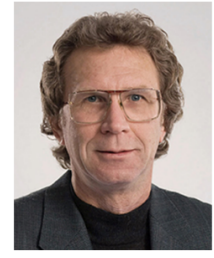

Rollin McCraty, Ph.D., Executive Vice President and Director of Research. Rollin McCraty of Boulder Creek, Calif., is executive vice president and director of research of HeartMath Institute. McCraty is director of research and project coordinator of the Global Coherence Monitoring System. He has been with HeartMath since its creation in 1991. He is a psychophysiologist and a professor at Florida Atlantic University. McCraty's research interests include the physiology of emotion, with a focus on the mechanisms by which emotions influence cognitive processes, behavior and health. He and his team regularly participate in studies with scientific, medical and educational institutions worldwide. McCraty has written extensively and been widely published in his areas of scientific interest. He holds numerous memberships, including with the American Autonomic Society, Pavlovian Society, National Association for Psychological Science, Association for Applied Psychophysiology and Biofeedback and Society for Scientific Exploration.

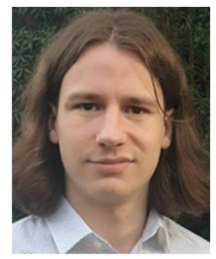

Vilius Pèstininkas is studying Mathematics with Finance Bachelor's degree in The University of Manchester. Being a final year student, Péstininkas remained active throughout his studies participating in numerous societies and has worked in Finance related areas in companies such as Ernst \& Young.

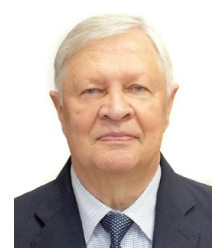

Alfonsas Vainoras received Ph.D. in biomedical sciences, medicine, in 1980. Habil. Dr. defends on 1996. Now is working in Institute of Cardiology, Lithuanian University of Health Sciences. Is working on ECG nonlinear analysis and is studying local magnetic field and human health interactions. 